\title{
Hemoptisis por secuestro pulmonar intralobar en adultos
}

\section{Hemoptysis due to intralobar pulmonary sequestration in adults}

\section{José Alfredo Ramírez-Ramírez ${ }^{1}$ Oscar Galloso-Cervantes ${ }^{2}$}

1. Servicio de Cirugía de Tórax y Cardiovascular del Hospital Nacional Cayetano Heredia.

2. Servicio de Neumología del Hospital Nacional Cayetano Heredia.

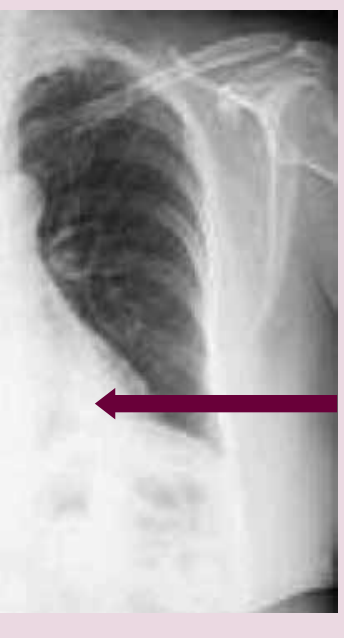

Figura 1. Radiografía anteroposterior del tórax. Flecha señala doble densidad en la silueta cardíaca.

vida del paciente. ${ }^{4}$ Presentamos un caso de una paciente de 55 años de edad con hemoptisis recurrente desde los 15 años de edad. La hemoptisis es el tercer síntoma más frecuente en $\mathrm{SP}^{3}$ La radiografía y tomografía torácica (figura 1 y 2) mostraron una lesión de masa en parte posterior de base pulmonar izquierda (Figuras 1-3,). De los SP, 49 \% se muestran como lesión de masa. ${ }^{1}$ La angiotomografía torácica mostró una arteria proveniente de aorta abdominal antes del origen del tronco celiaco y que desembocaba en la lesión de masa intratorácica previamente durante la cirugía por desgarro involuntario de arteria aberrante que puede comprometer la

En casos de SP debe realizarse una planificación quirúrgica cuidadosa en base a imágenes radiológicas a fin de evitar sangrado importante

Recibimos por emergencia a una paciente de 55 años quien presentó hemoptisis moderada. En su historia pasada refirió haber presentado el mismo cuadro en cuatro oportunidades desde los 15 años de edad. No refirió contacto con pacientes tuberculosos. Ha sido hospitalizada por el mismo motivo en otro hospital hace 20 años. Al examen físico no se hallaron signos significativos. Las masa en base posterior del hemitórax izquierdo. (Figura 1). La tomografía torácica mostró una lesión de masa en base del hemitórax izquierdo. Se le indicó angiografía torácica. En el examen se abdominal por encima del tronco celiaco y que maba en la lesión de masa basal izquierd de la paciente y través de una toracotomía posterolateral el sexto espacio intercostal lo previa identificación ligadura y sección de arteria aberrante.

\section{DISCUSIÓN}




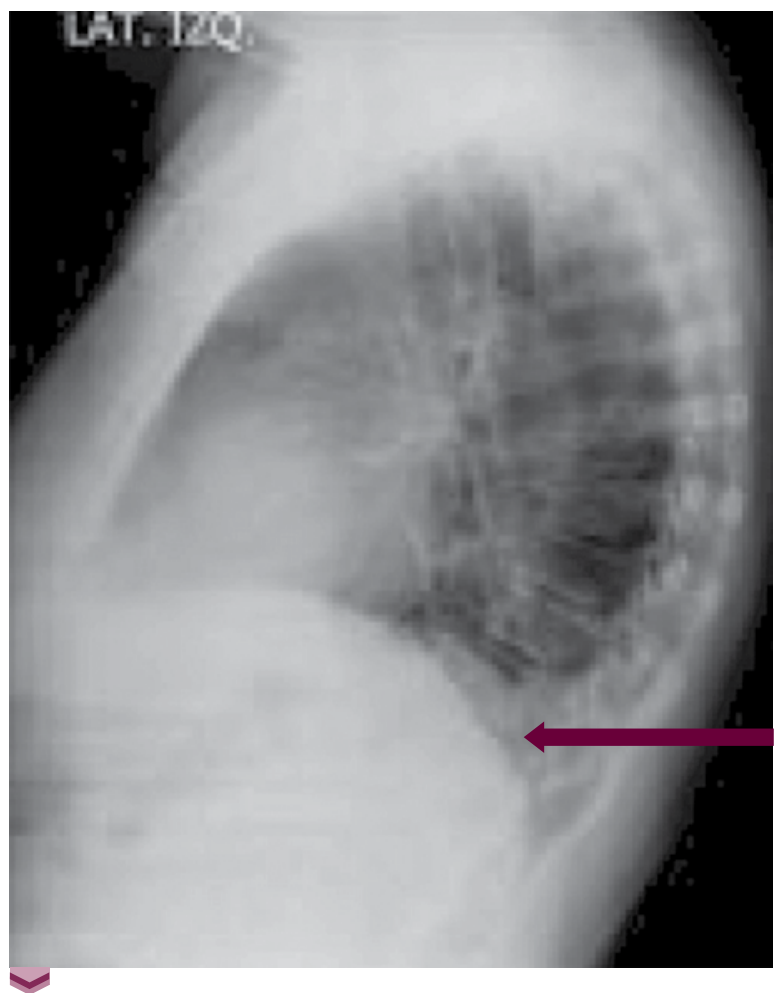

Figura 2. Radiografía lateral izquierda del tórax. La flecha marca zona de opacidad posterobasal.

definida. En lesiones de masa en bases pulmonares de preferencia izquierda en adultos con sintomatología respiratoria desde temprana edad se debe plantear el diagnostico de SP. ${ }^{4} \mathrm{El}$ diagnóstico de SP esta dado por la demostración de la presencia de una arteria aberrante. La forma más efectiva para hallar una arteria aberrante es una angiotomografia. ${ }^{5}$ La demostración de la arteria aberrante define el diagnostico de SP y permite establecer una estrategia quirúrgica adecuada. Electivamente se efectuó lobectomía inferior izquierda previa identificación ligadura y sección de arteria aberrante.

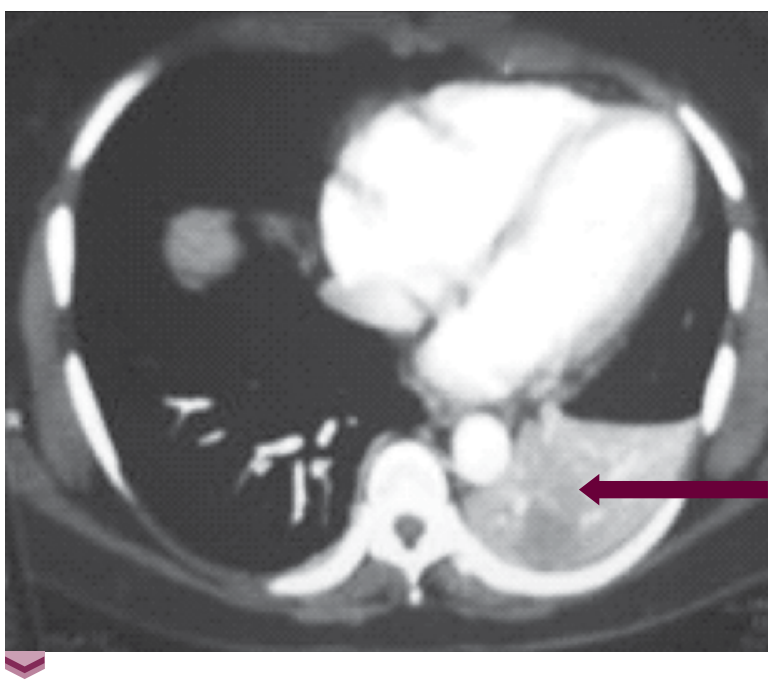

Figura 3. Tomografía torácica. La flecha muestra una lesión de masa.

\section{REFERENCIAS}

I. Chandrakanth A, Brock M. Pulmonary sequestrations. Lung congenital anomalies. In:Yang SC, Cameron DE. Current therapy in thoracic and cardiovascular surgery. 2004.

2. Siddiqui $\mathrm{NH}$, Husain AN. Lung and pleura. In: Haber $\mathrm{MH}$. Differential diagnosis in surgical pathology. Philadelphia: WB Saunders Company; 2002.

3. Yong Wei, Fan Li. Pulmonary sequestration: a retrospective analysis of 2625 cases in China. Eur J Cardiothor Surg. 201 I;40:e39-e42

4. Savic B, Birtel FJ, Tholen W, Funke HD, Knoche R. Lung sequestration: report of seven cases and review of 540 published cases. Thorax, 1979, 34, 96-101

5. Gustafson, et al. Intralobar sequestration: a missed diagnosis.Ann Thorac Surg. 1989;47:84I-84

6. Tashtoush B, Memarpour R, Gonzalez J, Hadeh A, Ferrer G, Smolley L. Pulmonary sequestration: case series review of 29 patients in the Cleveland Clinic Health System st. Cardiothor Surg. 2014;146(4) _ MeetingAbstracts 2014;146(4_ MeetingAbstracts):92A. doi:10.1378/chest. 1983679

\section{Correspondencia}

Acta Médica peruana

actamedicaperuana@fondoeditorial.com 